\title{
Supporting Self-Regulated Learning
}

\author{
Alexander Nussbaumer, Ingo Dahn, Sylvana Kroop, \\ Alexander Mikroyannidis, and Dietrich Albert
}

\begin{abstract}
Self-regulated learning (SRL) competences are crucial for lifelong learning. Their cultivation requires the right balance between freedom and guidance during the learning processes. Current learning systems and approaches, such as personal learning environments, give overwhelming freedom, but also let weak learners alone. Other systems, such as learning management systems or adaptive systems, tend to institutionalise learners too much, which does not support the development of SRL competences. This chapter presents possibilities and approaches to support SRL by the use of technology. After discussing the theoretical background of SRL and related technologies, a formal framework is presented that describes the SRL process, related competences, and guidelines. Furthermore, a variety of methods is presented, how learners can be supported to learn in a self-regulated way.
\end{abstract}

Keywords Self-regulated learning • Learning guidance • Learning models • Personal learning environments

\author{
A. Nussbaumer $(\triangle)$ \\ Knowledge Technologies Institute, Graz University of Technology, Graz, Austria \\ e-mail: alexander.nussbaumer@tugraz.at \\ I. Dahn \\ Knowledge Media Institute, University of Koblenz-Landau, Koblenz, Germany \\ e-mail: dahn@uni-koblenz.de \\ S. Kroop \\ Zentrum for Social Innovation, Vienna, Austria \\ e-mail: kroop@zsi.at
}

\section{A. Mikroyannidis}

Knowledge Media Institute, The Open University, Milton Keynes, UK

e-mail: alexander.mikroyannidis@open.ac.uk

D. Albert

Knowledge Technologies Institute, Graz University of Technology, Graz, Austria

Department of Psychology, University of Graz, Graz, Austria

e-mail: dietrich.albert@tugraz.at

S. Kroop et al. (eds.), Responsive Open Learning Environments,

DOI 10.1007/978-3-319-02399-1_2 


\section{Introduction}

The ROLE project ${ }^{1}$ has aimed to achieve progress beyond the state of the art in user-centric responsive and open learning environments, which included psychopedagogical models beyond instructional design. ROLE was researching and developing a psycho-pedagogical framework for supporting the individual composition and usage of learning environments. The most important goal of this framework is to support learners to learn in a self-regulated way in responsive open learning environments.

The self-regulated way of learning ${ }^{2}$ is a fundamental aim for ROLE. The reason for this aim is the orientation towards lifelong learning, which means that learning with ROLE takes place across institutional boundaries. This includes consideration of formal, non-formal, as well as informal learning. These dimensions of learning organisations are seen as fluent, rather than as rigid categories.

In order to manage the challenge of learning on their own in the ROLE context, learners require certain self-regulated learning (SRL) competences. For this reason, ROLE aims at enhancing this kind of competences by providing support strategies on different levels depending on the learner's needs and competences. Basically the support strategy depends on the learning situation. In a blended learning situation a teacher or tutor plays an important role for supporting SRL, in a collaborative situation peers play a role and have influence on the learning trajectory, and finally technology-mediated approaches play a role in all learning situations. All of them can be interconnected and the support strategy depends on the respective situations.

This chapter is widely based on ROLE deliverables, especially Deliverable D6.1 (Nussbaumer et al. 2013) has been taken into account. The remainder of this chapter is structured as follows: Section "Theoretical Background" gives an overview on the theoretical background of SRL. Learning technology and its relation to SRL is described in section "Related Work and Technology". Section "Models and Framework" presents the general framework on SRL and includes several models. A variety of guidance strategies are listed in section "Support Strategies". The experiences made at the ROLE test beds and in several workshops with students and researchers are reported in section "Evaluation Results, Challenges, and Barriers". Finally, the conclusion section summarises the key findings.

\section{Theoretical Background}

From a psycho-pedagogical point of view, SRL is a complex field of research that combines motivational as well as cognitive and personality theories. Components of SRL are cognition, meta-cognition, motivation, affects, and volition (Kitsantas 2002).

\footnotetext{
${ }^{1}$ http://www.role-project.eu/

${ }^{2}$ See self-regulated learning teaser video, http://www.youtube.com/watch?v=jTa1vOH6JjA.
} 
According to Zimmerman (2002), students can be described as self-regulated to the degree that they are meta-cognitively, motivationally, and behaviourally active participants in their own learning process. To define students' learning as self-regulated, they have to use specific strategies for attaining their goals and all this has to be based on self-efficacy perceptions. In this context there are mainly three elements important, namely the SRL strategies of students, their perceptions of self-efficacy regarding their performance skills, and the commitment to their goals. The learners are active and able to control, monitor, and regulate their cognition, motivational state, behaviour, and context. Furthermore, the learners set goals and try to achieve them through progress-monitoring. These self-regulatory activities are mediators between personal characteristics, contextual features, and actual performance in the learning process. In a meta-analysis conducted by Hattie (2009), it turned out that performing selfregulatory activities in the learning process is one of the most effective methods to reach the learning goals.

Zimmerman has developed a cyclic SRL model (Zimmerman 2002) consisting of three phases, which are the forethought phase (goal setting or planning), the performance phase (self-observation processes), and the self-reflection phase (self-reflection processes). According to this model, learning performance and behaviour consist of both cognitive and meta-cognitive activities. The cognitive activities are related to dealing with subject domains, for example, acquiring domain knowledge through reading. The meta-cognitive activities are related to thinking about and regulating the cognitive activities, for example, making a plan about domain knowledge acquisition.

A similar approach is pursued by Boekaerts (1999) who developed the layered SRL model consisting of three layers. The first layer is about the regulation of the self, which is related to the choice of goals and resources. The second layer focuses on the regulation of the learning process that relates to the use of meta-cognitive skills to direct the learning process. The third layer describes the regulation of the processing modes, which describes the choice of cognitive strategies. Also this model deals with cognitive and meta-cognitive activities, as well as with goals and resources.

A key role in SRL is given to learning activities that are also called learning strategies or learning processes. Dabbagh and Kitsantas (2004) listed six key processes that are essential for SRL, namely goal setting, self-monitoring, selfevaluation, task strategies, help-seeking, and time management.

- The goal setting process is defined as the outcome of a learning process and identifies strategies how to reach these goals. Goal setting motivates the learner's choice of and attention to the relevant tasks and it also motivates to attain higher effort and higher persistence over the course of time (Zimmerman 2002). Furthermore, goal setting influences learning through affective reactions, for example, higher self-satisfaction when goals are reached. Also the difficulty of a goal is an important factor for performance that increases with the difficulty level of the goal (Locke and Latham 2002). 
- Self-monitoring is defined as one's reflected attention to an aspect of behaviour that directs the learners' attention to the task and assists them in evaluating the outcomes of their efforts. Self-monitoring is important because it helps learners attaining their goals by defining adequate learning adjustments.

- Self-evaluation is the process where the learner compares the learning outcome with their own goals. It fosters better skill acquisition, self-efficacy beliefs, intrinsic interest, and self-satisfaction about performance.

- Task strategies is defined as the process of the learner who applies strategies which help reach their own goals. Studies indicate that students who applied strategies for learning had a better performance than students who did not apply them as much (Pintrich 1990).

- Help-seeking is taking place if a learner identifies and calls upon outside resources. Thereby not only human help is meant, but also external analogue and digital resources.

- Time management is the process where learners manage the learning regarding time. Effective time budgeting highly correlates with academic achievement.

According to Roberts and Erdos (1993), meta-cognition is a key concept in the study of cognition and it plays an important role in the transfer of cognitive skills and in problem solving. Meta-cognition refers to knowledge and cognition about one's own cognition. According to Treier (2004), meta-cognition is a kind of selfmonitoring, self-observation, and self-regulation related to cognitive and information processing. Meta-cognition is the competence of reflecting a mental task critically and to organise involved learning and thinking processes in an efficient and effective way. The usage of meta-cognitive learning strategies is an essential component of SRL and is very important for flexibilisation and personalisation.

Taking into account the learner's characteristics by individually adapting learning methods has a big influence on the learner's performance (Issing 2002). The importance of the adaptation to the learner's characteristics (also called personalisation) was shown in several studies. For example, the adaptive subject material combined with adaptive styles of presentation supports students to improve their learning achievements and increases learning efficiency (Tseng et al. 2008). Furthermore, the importance of adaption to individual learning preferences of a learner regarding visualisation and verbalisation has been proven (Plass 1998). Through a requirement analysis it has been found out that the learner's knowledge, goals and tasks, language, interests, and learning styles are important factors of personalisation approaches (Hover and Steiner 2009).

Supporting SRL in the right way is a crucial factor. On the one hand, it means providing enough freedom for the learner, in order to stimulate motivation. However, on the other hand, too much freedom may be overwhelming and an appropriate guidance or even adaptation is usually needed to make the learning process effective and efficient. The concept of guidance and freedom is important because it has been recognised that highly motivated learners attain a better learning performance if they have more control over their learning and are more autonomous (Issing 2002). On the other hand, some learners show difficulties in carrying out 
concrete meta-cognitive activities, such as planning, goal setting, monitoring, evaluating, and as a result often perform less successfully than would be anticipated (Bannert 2006). Such learners are in need of guidance when learning. Furthermore, less motivated learners can also attain an improved learning performance if they receive more guidance. Keeping these reported findings in mind, the individual support for learners should be tailored to suitable degrees of guidance and freedom. In this respect, the learner should be offered an optimal and balanced level of control and autonomy for their own learning process.

Motivation is a highly relevant aspect for achieving good learning outcomes and for performing SRL activities. Winne and Hadwin (2008) showed the positive impact of motivation on student's attention to their learning progress, on the progress itself, and on the experience of satisfaction and positive affect. For the use of SRL activities, a learner has to be motivated as these activities require additional time and effort. Ryan and Deci (2000) describe intrinsic motivation as one of the most important aspects regarding learning because it is the prototypical manifestation of the human tendency towards learning and creativity. Behaviours of intrinsically motivated learners are freely applied without the necessity of separable consequences. For intrinsic motivation to develop, there is need for autonomy, competence, and relatedness. However, there is also a need for extrinsic motivation and especially a good balance between extrinsic and intrinsic motivation (Covington 2000)

Another important factor for SRL is collaboration. According to Dillenbourg (1999), collaborative learning comprises individually performed activities and also extra activities that are generated by interaction among peers. These collaborative activities trigger additional cognitive mechanisms, which may appear more frequently in collaborative learning situations than in individual learning. Students working in cooperative learning situations compared to individualistic or competitive learning situations have a higher performance at the mastery and retention of material, are more often using focusing, elaboration, and meta-cognition strategies, and develop ideas or solutions which are not gained if they work on their own (McConnell 2000). Collaboration can also create both intrinsic and extrinsic motivation and is an essential strategy for stimulating curiosity, emulation, attention, persistence, opening new perspectives, and increasing self-efficacy (Waite and Davis 2006).

All these aspects are relevant for the psycho-pedagogical approach of ROLE. The process model and related cognitive and meta-cognitive learning activities have been explicitly modelled. The concept of guidance and freedom as well as adaptation is achieved through recommendations of activities and resources. Other concepts, such as motivation and collaboration, are implicitly targeted through the use of technology. 


\section{Related Work and Technology}

This section gives a short overview on technology-enhanced learning (TEL) solutions discusses them from the SRL perspective. Technology plays an important role for SRL because it has been reported that TEL environments can provide opportunities to enhance SRL competences for students, especially meta-cognitive competences (Bannert 2006).

Since the early 1970s, researchers have adopted the educational model of human tutors and started to implement it in intelligent computer-based instructions (Corbett et al. 1997). The goal of those Intelligent Tutoring Systems (ITS) was to engage students in learning activities and to interact according to their behaviour. ITSs were supposed to bring intelligence to computer-based instruction, especially in the knowledge of the subject domain as well as the tutoring principles and methods of their application (Anderson 1988). This led to the development of four basic components: the domain model, the student model, the tutoring model, and the user interface model. An important research strand is also the work on adaptive hypermedia and adaptive Web and how it is applied in the educational context (Brusilovsky et al. 2007). Strategies and systems (e.g. as described in Albert and Schrepp (1999) and DeBra et al. (2006)) have been developed that aim to adapt its content and behaviour to the individual student. In the light of SRL, these solutions do not support the learner. They do not allow freedom or autonomy, but guide the learner through the learning process. They also do not give any hint or explanation regarding SRL.

A different development of TEL solutions is Learning Management Systems (LMS). They primarily focus on distributing learning content, organising the learning processes, and serving as interface between learner and teacher. In educational institutions LMSs have become very popular and are used in many universities and schools (Paulsen 2003). Examples of LMSs are Moodle, CLIX, Blackboard, WebCT, Sakai, ILIAS, and LRN. They all have in common that different tools are integrated in a single system, such as discussion forums, file sharing, whiteboards, chat, and e-portfolios (Dalsgaard 2006). These tools together with learning content are bundled by teachers or tutors, leading to a centralised and standardised learning experience (Guo et al. 2010). In contrast to ITSs or adaptive systems, no automatic guidance is provided by LMS. The guidance the learners get is provided by teachers or instructors who prepare courses. On the other hand, learners have more freedom and autonomy through some tools integrated in LMSs. For example, collaboration tools allow to discuss certain topics.

In contrast to an LMS, personal learning environments (PLEs) strive for a more natural and learner-centric approach. PLEs are online systems that combine services as well as tools that enable users to create their own customised learning system. The teacher is no longer the provider of knowledge, but rather a mediator between knowledge and students. On the other side, the student is responsible for organising information and their own learning. In recent years, attempts have been made to build PLEs based on mashup designs. An example based on social media 
tools is eMUSE (Popescu and Cioiu 2011), which integrates Web 2.0 tools into a single system. It claims that such tool integration leads to a sense of community and thus increases success and retention rates. Furthermore, eMUSE offers support for self-monitoring and self-evaluation by providing feedback on learning tasks, which is supposed to increase learning success and motivation. A further example is the PLE developed at the Graz University of Technology (Ebner and Taraghi 2010). This PLE allows for selecting widgets from a repository and adding them to a personal space. Besides some general purpose widgets (similar to the tools in an LMS), domain-specific widgets have been created by students in university courses. It also allows for logging and analysing students' activities performed on these PLEs (Softic et al. 2013). Users can manage their PLE and, therefore, take greater control of their own learning approach.

Specific technology that aimed supporting SRL was developed in several research projects. For example, the iClass project aimed at developing an intelligent, cognitive-based open learning environment that supports the planning, monitoring, and reflection processes of a learner and at the same time personalise the learning process to the respective learners' preferences and needs (Aviram et al. 2008). In order to achieve personalised recommendations and reflection support, a competence model has been used that is basis for individual guidance (Steiner et al. 2009). This competence model is based on Competence-based Knowledge Space Theory (CbKST) (Heller et al. 2006) that structures competences through prerequisite relations. Visualisation tools have been created that display the competence structures and let the learner select learning goals and learning paths (Nussbaumer et al. 2008).

The ROLE approach differentiates from these solutions in the way that it provides a maximum of technical flexibility and provides personalised learning support at the same time. A psycho-pedagogical model is integrated with the technology, which leads to range of freedom and guidance to be chosen by the learner.

\section{Models and Framework}

\section{Self-Regulated Learning Process Model}

A process model (Fruhmann et al. 2010) has been developed that takes into account requirements of the ROLE approach to create and use responsive open learning environments that support SRL. The SRL process model describes learning as a self-regulated process consisting of four learning phases: (1) defining or revising the learner's profile information and setting up an initial individual learning plan, (2) finding and selecting learning resources, (3) working on selected learning resources, and (4) reflecting on the applied strategies and reached achievements. The model is depicted in Fig. 1. This approach follows the cyclic SRL model proposed by Zimmerman (2002) and was slightly extended and modified. First, the 


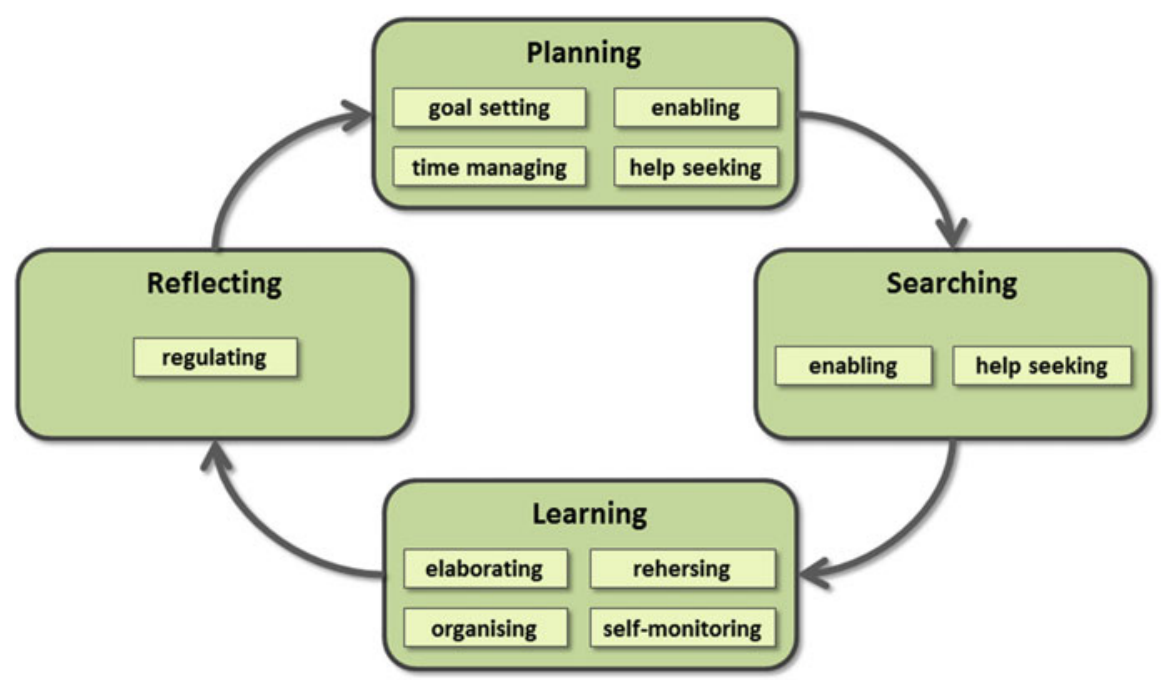

Fig. 1 SRL process model. This diagram depicts the SRL process model and related strategies

phase when learners create their own learning environment is considered as a separate phase because this is a central part of ROLE. In the Zimmerman model this phase would be related to the forethought phase. Second, the personalisation aspect has been included by defining a user model consisting of models for describing competences, learning activities, and goals.

In addition to these phases, a taxonomy of learning strategies, learning techniques, and activities has been defined, in order to operationalise the four phases. The phases are associated with learning strategies (see Fig. 1) and each strategy is related to learning techniques and learning activities. We consider learning activities as the applications of learning techniques. This approach is based on the work of Dabbagh and Kitsantas (2004) on SRL processes and Mandl and Friedrich (2006) on SRL strategies and techniques. These findings have been adapted and integrated, in order to serve as a comprehensive and integrated model for technology-support.

Using this theoretical background, we have defined nine SRL strategies and structured them in three groups, which are cognitive strategies, meta-cognitive strategies, and resource management (see Fig. 2). The group of cognitive strategies include organisation, elaboration, and rehearsal tasks of learning topics. The group of meta-cognitive strategies include goal setting, self-monitoring, and regulation tasks targeting the control of the own learning process. The group of resource management strategies include time management, help-seeking, and enabling (or environment preparation), which means that learners take care for their learning resources. These strategies are connected to SRL phases, which enrich the meaning of these phases with a clearer notion. For the instantiation of learning strategies and learning techniques, two complementary approaches have been used.

For each of the nine listed learning strategies, a variable number of learning techniques are assigned. For instance, elaboration can be done with the following 


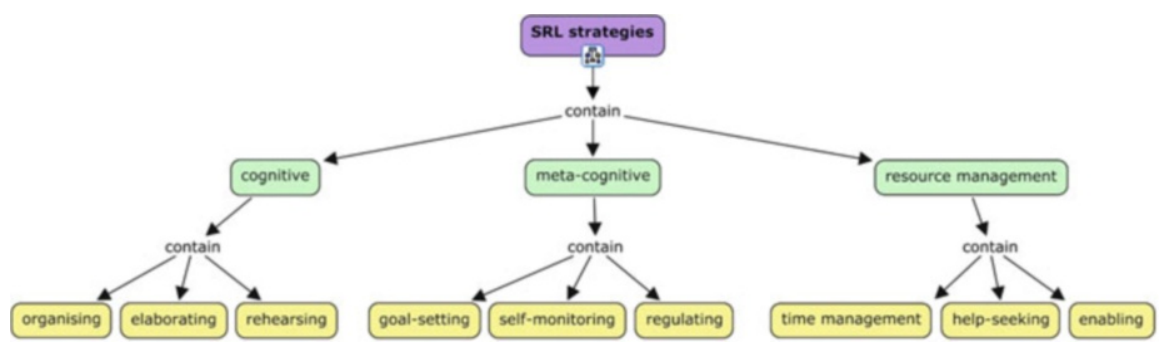

Fig. 2 SRL Strategies. This diagram displays the SRL strategies and their relations to each other

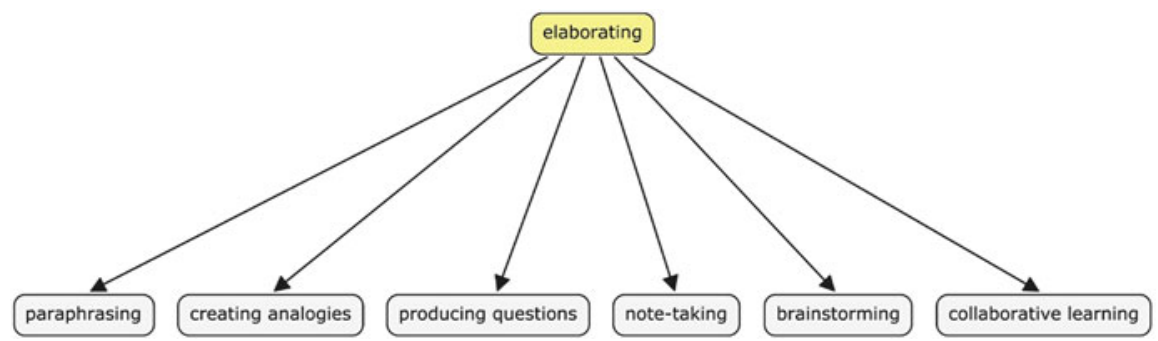

Fig. 3 SRL techniques. This diagram gives an example of an SRL strategy and six associated learning techniques

learning techniques: paraphrasing, creating analogies, producing questions, notetaking, brainstorming, and collaborative learning (see Fig. 3). A complete list of learning techniques and their assignment to the SRL strategies can be found in the ROLE ontology (see section "Learning Ontology").

\section{Applying the SRL Process Model}

Using ROLE learning environment learners are interacting with a learning environment that provides various resources like contacts to other actors, appropriate tools/ services, and suitable artefacts for the acquisition of knowledge, skills, and the fostering of competence development. For the personalisation and the preparation of a learning environment, learners have to set up their learning space in a meaningful. Especially in SRL situations, where learners take responsibility for the learning process and learning outcomes, the competent application of learning strategies is considered helpful for learners and can lead to better learning performance (Weinstein et al. 2005).

In SRL situations the definition of the learning goal before the selection of learning tasks and the application of learning activities is very important. If learners 


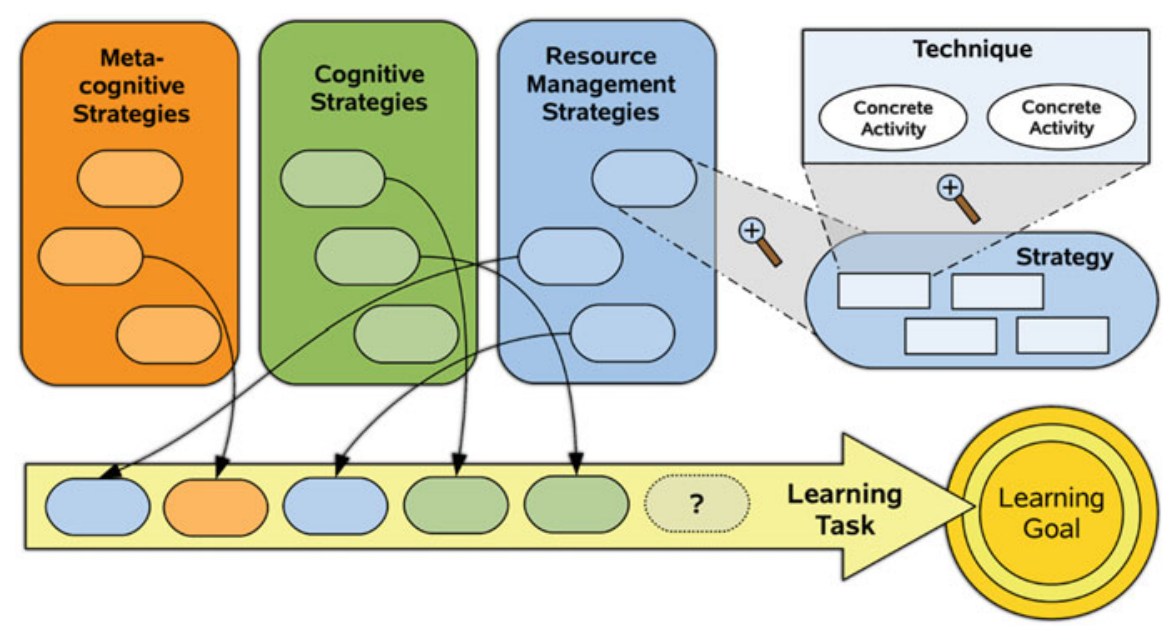

Fig. 4 Applying SRL strategies and techniques. This figure explains how SRL strategies and learning techniques are applied in the learning process to achieve a learning goal

are not aware of their learning goals and if they do not know how to reach them, learners incline to apply more or less habitual learning strategies that may not be appropriate for processing a learning task instead of adapting or making up new strategies. The SRL process model and the related learning strategies and techniques are used to guide the learning through the learning process (see Fig. 4). First learners set a goal. Then they choose from a set of cognitive, meta-cognitive, and resource management strategies. The strategies are related with respected learning techniques and learning tools. In this way a sequence of learning activities (strategies and techniques) is created that should lead to reach the learning goal. Through recommender systems (see section "Support Strategies") the learner can get help during the selection process.

\section{Competence Model}

A competence model consisting of different kinds of competences takes into account domain knowledge, the ability to learn with tools, and SRL competences. The distinction of the competence types originates from the fact that learning happens on different levels. We distinguish between (1) domain knowledge and related competences, (2) the ability to learn with specific tools, and (3) the ability to 
learn in a self-regulated way. Therefore, three types of competences are defined: domain competences, tool competences, and SRL competences.

The domain competence describes the knowledge of a learner regarding a certain domain-specific topic. In detail a concept (e.g. from a concept map) is assigned with a level from the European Qualifications Framework (EQF). ${ }^{3}$ The tool competence defines the ability how a learner can apply a learning technique with a certain tool functionality. Formally spoken, a tool competence is a pair of a related learning technique and an EQF level. For example, it can be defined how well a learner can debate with a tool that allows for video conferencing. The SRL competence defines the ability regarding one of the nine learning strategies described above.

\section{Learner Model}

In adaptive systems, user models are often designed as overlay models where user information relies on and is described by conceptual information (e.g. concept maps). Our learner model follows this scheme, but also relies on the learning taxonomy and its elements. This is necessary as the information about the learner is not only given at domain level, but also on the level of cognitive and metacognitive activities (the application of the learning strategies and techniques). The learner model consists of four elements. First, the competence state describes the available competences of the learner taking into account that there are three different types of competences. Thus, a learner is assessed regarding domain knowledge, the ability to learn with tools, and the ability to learn in a self-regulated manner. Second, the goals of a learner are also described with these competences, e.g. the learning goal is expressed in terms of the competences a learner wants to achieve. Third, the learning history is described by the learning activities (applied strategies and techniques) a learner has performed, the tools or widgets she has used, and the competences she has attained. In contrast to plain log data, this learning history provides more insight because it describes the history in terms of learning not just the particular interactions, but also regarding learning activities and used resources. Fourth, pedagogical parameters describe individual preferences and properties of the learner. Examples are information about preferred tools, learning groups, or guidance mechanisms. An overview is given in Fig. 5.

\footnotetext{
${ }^{3} \mathrm{http} / / /$ ec.europa.eu/education/lifelong-learning-policy/eqf_en.htm
} 


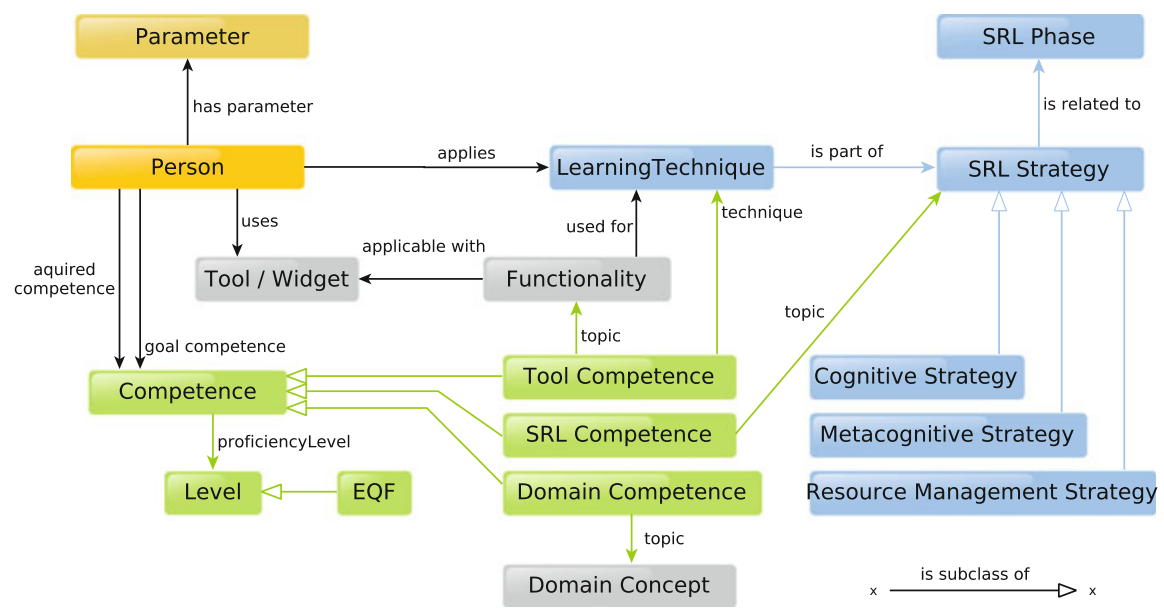

Fig. 5 Competence ontology. This diagram depicts the relevant elements of the competence model and how they are technically interrelated

\section{Learning Ontology}

The formal representation of the models listed above (competences, strategies, techniques, goals) is expressed as ontology in $\mathrm{RDF}^{4} / \mathrm{OWL}^{5}$ format and consists of the classes and properties. An overview of this ontology is depicted in Fig. 5. More details on the learning ontology can be found in Dahn et al. (2013). The Competence class is the superclass of the three types of competences. It allows specifying title and description via reusing the title and description properties from the Dublin Core ${ }^{6}$ terms vocabulary. Furthermore, it provides two properties that allow for a generic definition of the competence. First, a topic property is used to relate a specific competence with a generic object (owl:Thing). Secondly, the proficiencyLevel property is used to express the extent to which a user has a specific competence. The generic Level class is subclassed by the EQF class to indicate the competence level.

In order to relate a competence to a learner, a Person class is used that has the properties acquiredCompetence, goalCompetence, uses, applies, and hasParameter.

In this way competences are defined that a learner has already acquired and competences that a learner should attain, the tools a learner has used, the learning techniques she has applied, and the personal preferences. The DomainCompetence class allows for defining a domain competence. It is a subclass of the Competence class and inherits title, description, topic, and EQF level specification. In this way

\footnotetext{
${ }^{4}$ http://www.w3.org/RDF/

${ }^{5}$ http://www.w3.org/TR/owl-overview/

${ }^{6}$ http://dublincore.org/
} 
competence can be defined by using the topic property to assign the related domain concept and the proficiencyLevel property to define the EQF level. The ToolCompetence class allows for defining a tool competence. It is a subclass of the Competence class and inherits the title and description specification. Following the definition of tool competences, the topic property is used to relate tool functionalities and the technique property is used to relate a LearningTechnique. The SRLCompetence class allows for defining SRL competences. It is a subclass of the Competence class and inherits the title and description specification. Following the definition of SRL competences, the topic property is used to relate to SRL strategies and the inherited proficiencyLevel property is used to relate an EQF level. Since SRL competence can be related to different types of SRL strategies (cognitive, meta-cognitive, and resource management strategies), appropriate subclasses of the SRLStrategy class have been defined.

\section{Mashup Guidelines}

The mashup of a learning environment is an important feature. It can affect the way of learning not only by its pure use, but how it is compiled. It is assumed that compiling widgets to a learning environment or bundle relate to different psychopedagogical aspects and educational components. Taking into account these educational components, some essential guidelines have been developed to provide the learner with recommendations for a psycho-pedagogically sound mashup (Berthold et al. 2012). These guidelines should be taken into account by the learner creating a bundle for herself and by teachers or tutors creating bundles for learners. It is also a basis for recommender technology that can apply these guidelines.

Guideline 1: Cover all phases of the SRL process model: As described in section "Theoretical Background", learning is more successful if different cognitive and meta-cognitive strategies are applied. Hence, a mashup design should contain widgets that support different learning strategies. For example, one widget for each phase of the SRL process model. This could be materialised in a setting with a widget for goal setting, a widget for content searching, a widget to learn how to find content, and a widget where the learning process is reflected.

Guideline 2: Tool competence: Another educational component that comes into play is tool competence. Tool competences are abilities a learner has if she has knowledge about a tool, is able to perform a learning activity with a learning tool in a domain or domain-independent context, and is able to choose a tool or tool functionalities unassisted according to her learning or working task, e.g. the learner can use a tool for goal setting. If a tool competence is lacking for a certain widget, the learner will have problems to effectively use this widget.

Guideline 3: Number of widgets: The number of widgets and their different functionalities might overtax the learners, especially if they are not intrinsically motivated to perform the learning task. Hence, only an appropriate number of 
widgets should be added to a widget bundle. The range of the appropriate number of widgets within a widget bundle depends on the learner.

Guideline 4: Domain aspects: In the third phase of the SRL process model, the actual learning process takes place. This phase is influenced by learning goals. Learning goals are defined in the first phase of the SRL process model. Such learning goals are mostly domain specific and refer to a special context. Thus, widgets in the bundle should be in line with the domain aspects of the predefined learning goals.

\section{Support Strategies}

In the previous section it has been described how SRL can be operationalised. In this section concrete approaches are reported how SRL is supported by using the models and framework described above. They establish the ground basis for the technology and concepts to support learners in a scientifically driven way and provide learners with according technology and material to guide them through the learning process.

Learners who are able to understand the SRL process and the related learning activities and who are able to perform them on their own can navigate freely through their learning processes. However, this requires the availability of a high degree of SRL capabilities (availability of the respective SRL competences). Since it cannot be assumed that all learners already have these abilities, guidance mechanisms are needed. Such guidance is often needed especially when learning with technology-enhanced environments (Bannert 2006).

According to the experiences made in the test beds and at several workshops (see section "Related Work and Technology"), a variety of guidance strategies is necessary. Both technical and human support is needed depending on the learner and the situation. Additionally training and introductory material turned out as useful to increase initial motivation for new ways of learning.

\section{Motivational Video}

This section explains an initiative to make learners acquainted with SRL. According to our experience (in test beds and SRL surveys), the concept of SRL is new to most lectures and learners. Lifelong learning, non-formal learning, etc. are buzz words society talks about, but SRL is apparently a term more common in science and pedagogical research. For this reason, SRL needs to be introduced and actually promoted to learners, teachers, and a broader community to point out benefits of such a learning approach. An introduction can be done in many different ways. 

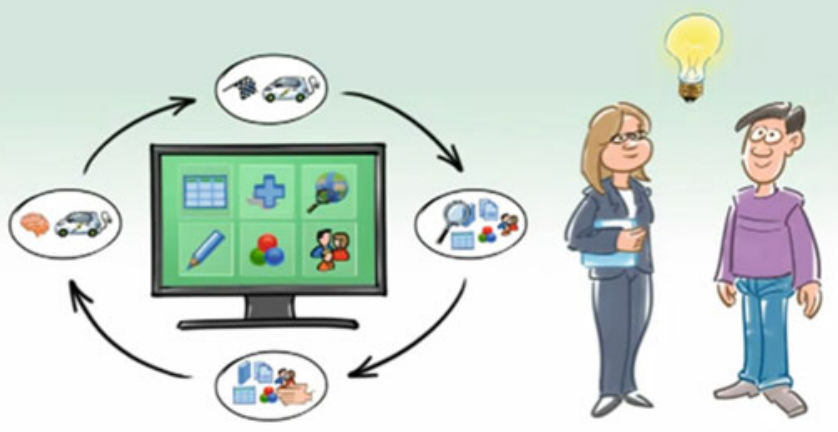

$13.11 / 3.39$

Fig. 6 SRL video. This figure is a screenshot of the video that introduces and explains SRL in the context of ROLE

Teaser videos were used to explain the concept of SRL on a basic level for learners who are completely new to SRL. A video ${ }^{7}$ has been created that focuses on the explanation of SRL by comparing it to a city travel (see Fig. 6). Two people are examining a city and its sights. While the first one is attending a guided tour, the second one defines the goals and plans on his own and does a city walk without external support. This analogy is explaining both the concept of self-regulation and the concept of guidance. Further videos have been developed in the course of the ROLE project, in order to explain different aspects of PLEs and SRL ${ }^{8}$. Especially, tutorial videos have been created that explain how to use ROLE technology.

\section{Courses and Training Material}

An SRL course is another method to reach learners and provide them with assistance and knowledge about SRL and SRL tools in a compact way. The goals of such a course are to introduce the idea of SRL and enable them to build their own learning environment. The content of such a course can be a brief SRL explanation, an explanation of different learning models or learning strategies, and how they can be used with ROLE technology.

At the Open University UK test bed such a course has been created as Online Course and as eBook. This course explains the basic concepts and also lets learners

\footnotetext{
${ }^{7}$ http://www.youtube.com/watch?v=jTa1vOH6JjA

${ }^{8}$ https://www.youtube.com/user/ROLEProject
} 
try out to create PLEs on their own. In this way learners can train SRL behaviour because they get step-by-step explanation and can try it out immediately.

\section{Preconfigured PLES}

Predefined PLEs are already compiled bundles of widgets to fulfil a certain learning need. Therefore, they are usually assembled with widgets that cover a certain domain (e.g. history, chemistry, or language learning). Such bundles are typically created by teachers or peers. Teachers have the chance to prepare a bundle suitable for the learning topic. In this way, the guidance is based on the preparation of whole bundles that are suitable for individual learners. A special case is Layered PLEs that consists of a set of widget bundles. Each set may be dedicated to a certain learning strategy of an SRL process phase.

\section{Widget Store}

The ROLE Widget Store is a Web-based online catalogue that allows to manage and index widgets. It provides a user-friendly interface to a widget repository that simplifies the discovery of widgets. The functionality of the widget store includes listings of widgets, categorisations, searching by widgets or keywords, and compilation of widgets into bundles. Users can add widgets from the widget store to PLE systems. From a social media point of view, the store is also the place to collect and share user tags, comments, and ratings. A widget creator and developer can add a widget to the store by adding its reference (URL) and metadata.

In order to provide guidance for learners in searching and selecting widgets for their PLEs, widgets can be tagged with metadata describing the purpose of the widgets. The first type of tags is a widget categorisation consisting of seven categories. The categories were derived from the SRL learning process model and are assigned to its phases. As described above a PLE should consist of widgets not only for one learning strategy, but widgets for different strategies should be included. The categorisation system is a useful way to follow this guideline because users get quick access to widgets for the specific purposes. They can browse the store and add widgets just by navigating to different categories.

In addition to the widget categories, functionalities described in an ontology are used to represent features of widgets (e.g. text editing, video chat). These functionalities are derived from a survey of existing widgets and from an analysis of the ontology. The SRL techniques are related to functionalities so that the ontology and the Widget Store share the same set of functionalities.

The third type of metadata is the domain concept describing widgets regarding a knowledge domain they are related to. Widgets can be either generic (e.g. text editor) or targeting specific learning domains (e.g. French language). As some 
widgets can hardly be described by tool categories or functionalities alone, a categorisation based on learning domains is introduced. The service of DBpedia ${ }^{9}$ is used to allow users the tagging of widgets by semantically unique learning domains supporting them in search for specific tools.

The user interface of the Widget Store allows for searching and filtering widgets according to categories, functionalities, and domain concepts. A list of widgets is listed according to the applied search. Additional filters can be applied regarding the metadata available for the listed widgets. The metadata for each widget is shown in the search result list, that is, category, functionalities, domain concepts, rating, title, and description.

\section{Mashup Recommender}

The Mashup Recommender widget (MR) (Fig. 7) can be seen as a filtering system that provides widgets that can be added to the PLE depending on the used template. The MR contains predefined templates, e.g. an SRL template. This template could include the four phases of the SRL process model. If the user selects such a phase, related widgets that support this phase are displayed. For example, if the learner selects the planning phase, calendar widgets, and To-Do-Widgets could be suggested by the MR. For this purpose, the MR uses SRL entities from the

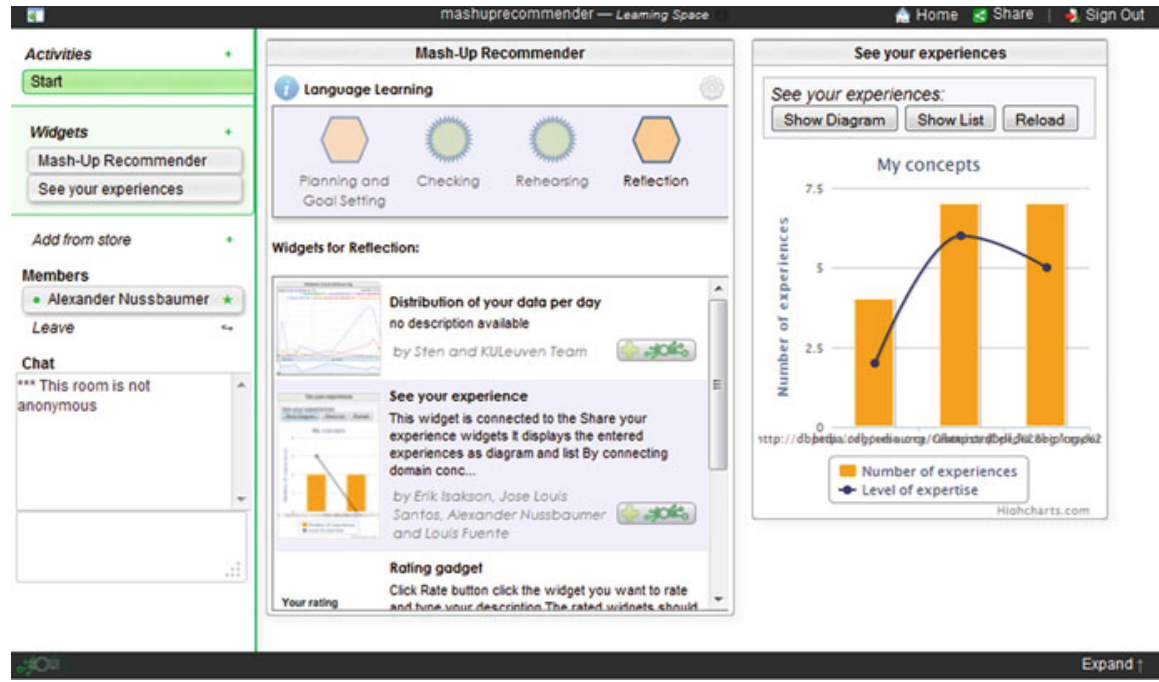

Fig. 7 Mashup Recommender. This screenshot displays the Mashup Recommender widget in the middle and a widget that was recommended on the right side

\footnotetext{
${ }^{9}$ http://dbpedia.org/
} 
ontology. The ontology service is questioned for the respective functionalities of the SRL entities (learning strategies, techniques, and activities) and the widget store returns the associated widgets. Such templates can be created using a special authoring tool.

The MR can be used to provide guidance on different levels and for different stakeholders. A high level of guidance is the preparation of complete predefined PLEs based on a specific template by a teacher or tutor. Later the tutor can share this PLE with her students who can use it or modify it. A lower level of guidance can be provided if the teacher just shares the template with the students, so that they have to create their own PLE. For example, a teacher could select the SRL entities goal setting, resource searching, note taking, and reflecting for a template. Teachers or learners using this template could easily search these SRL entities for widgets and include them in a PLE. In this way the PLE consists of widgets for each SRL entity. Learning strategies are on a higher abstraction level, which results in a greater number of widgets that can be recommended. Learning techniques are on a lower abstraction level, which leads to a smaller number of related widgets that can be recommended. While in the first case the learner gets more widgets recommended and thus less guidance, in the second case the level of guidance is higher because of the smaller number of recommended widgets. For a detailed description of the MR and its technical background, see Nussbaumer et al. (2014).

\section{Activity Recommender}

The Learning Activity Recommender guides the learner through the learning process by recommending learning activities related to the SRL process model. The learner is guided by means of a step-by-step approach of how to cope with a problem. In contrast to a direct instruction, the learner can decline to accept learning activities and can choose between alternatives and will not be penalised for varying his learning steps from what is suggested. The Activity Recommender (AR) consists of two widgets, the Activity Recommender widget and the To-Learn List widgets (Fig. 8).

In contrast to collaborative and content-based filtering approaches handling large community-generated data sets, the Activity Recommender is working with data predefined and structured by the educational experts according to the educational approach described in the last section. These experts prepare the recommendations by defining learning strategies, techniques, and matching activities for learning tasks using an authoring tool. The Activity Recommender guides the learners through the learning process by recommending learning activities and assists them to compile a learning plan. In contrast to direct instructions, the learners have a free choice which recommended learning activities they want to perform. When a learner has decided to use a recommended learning strategy, the respective learning activities can be sent from the Activity Recommender to the To-Learn list widget. The To-Learn list widget allows learners to compile an individual learning 


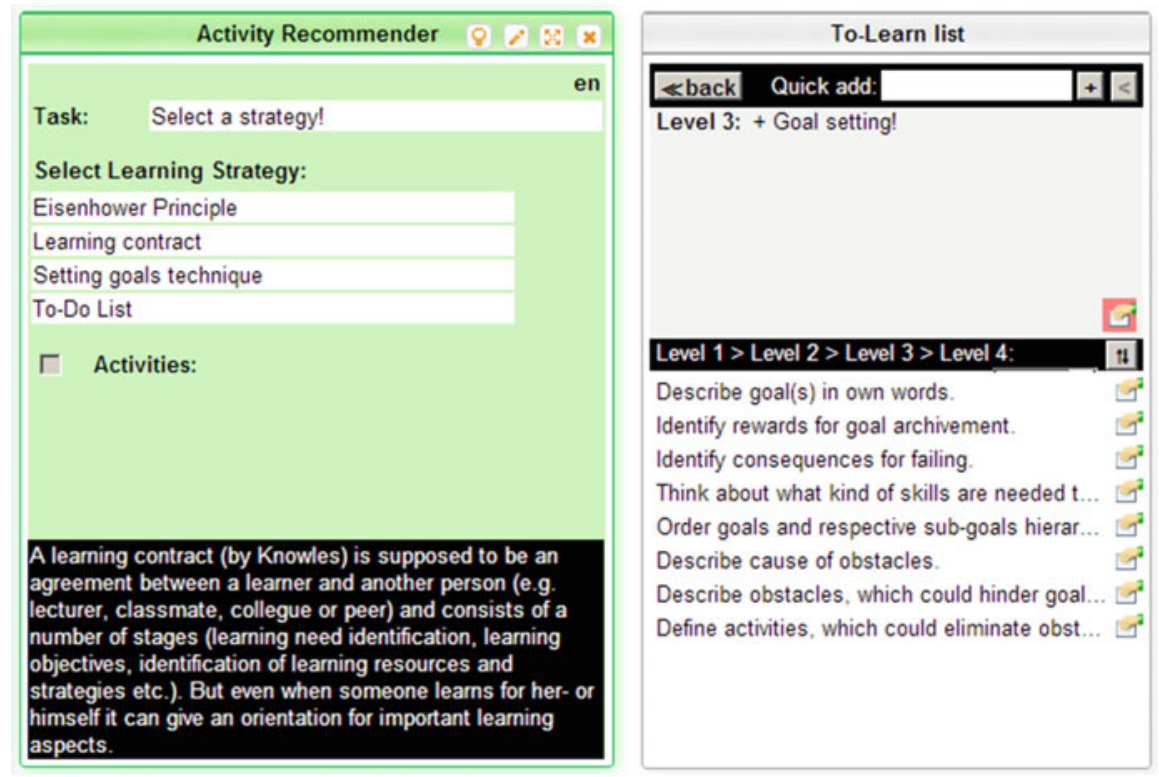

Fig. 8 Activity recommender. The To-Learn List widget and the Learning Activity Recommender widget are running in the ROLE SDK environment

plan. The widget enables to add, rearrange, delete, and rename recommended learning activities or to add own activities, e.g. reminding them to take a break after a brainstorming session. A learning activity is described with a short summary and a longer descriptive text. Every learning activity has a status that is either not started, started, completed, or cancelled. Moreover, it is possible to specify the learning activities by adding sub-activities on the lower hierarchy levels. Some of the activities are highlighted in red colour, which means there are further recommendations available for this activity. Displaying these recommendations can be triggered by clicking on a highlighted entry. Finally, the entries of the learning plan can be sorted by status, date, or manually.

\section{SRL Text Reader Bundle}

The SRL Text Reader Bundle (see Fig. 9) is a predefined widget bundle that supports SRL by providing feedback on the SRL activities. The bundle captures certain SRL activities and displays them in a graphical way to make the user aware about the activities she performs. The main widget is Text Reader where learners can read and annotate texts. These texts and related concepts are defined in a domain model on a backend service. The Self-Evaluation widget allows for relating the assigned tags with concepts from the domain model and to determine the proficiency level for each concept. In this way, the learner evaluates herself 

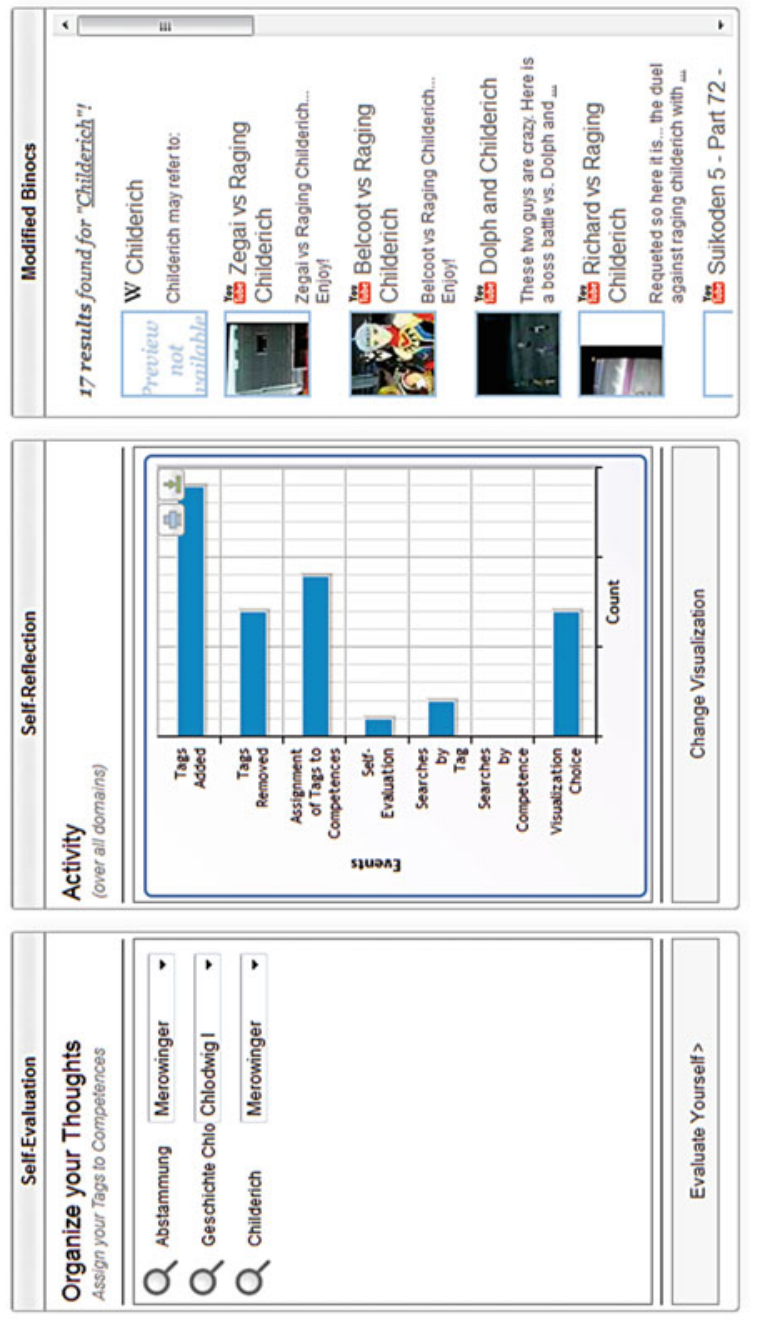

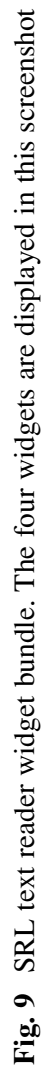


regarding her own domain competences. The search widget allows searching additional resources for the domain by searching related tags and concepts. All performed activities are recorded and stored in the user model. The visualisation widget follows an Open Learner Model approach and gives feedback to the learner about her learning process. In addition, the visualisation widget displays the texts that have been annotated and the concepts that have been used for self-evaluation. Guidance is provided by delivering a complete bundle of widgets that support the whole SRL process.

From the user model perspective some different types of information is saved for further usage. The activities a learner performed are saved using the activity schema outlined in the ontology definition in section "Support Strategies". The concepts coming from a domain model in the background and used for self-evaluation are stored together with the proficiency level as domain competence. The tags related to certain texts are saved as generic information. All this information is used for keeping the user data persistent and visualising the analysis in the Self-Reflection widget.

\section{SRL Monitor}

The SRL monitor provides support to develop self-awareness about the performed learning activities. The goal is not only to monitor and visualise the observable actions (as saved in log data), but also to monitor the cognitive and meta-cognitive activities that are not directly measurable. To this end, the measurable actions are mapped to cognitive and meta-cognitive learning activities from the ontology. To be precise, the key actions extracted from the log data analysis (based on an algorithm that clusters the log data) are mapped to elements of the learning ontology. The mapping is partially done by the learner herself, but also supported by an algorithm that takes into account the previous manual assignments. The goal is to make learners aware about their cognitive and meta-cognitive learning activities.

The screenshot displayed in Fig. 10 shows two views of the SRL Monitor. In the first view, the SRL Monitor displays the learner's captured log data in a sequence. Then the learner can select which learning technique she has actually applied. Based on these selections, reasoning is done regarding the applied learning strategies. Since there are only nine learning strategies, a comprehensive overview of the learner's behaviour can be given. This overview is graphically shown in the second view of Fig. 10. In this way learners get feedback about their learning behaviour and might rethink their learning process if some learning strategies never appear on the graphical profile. 

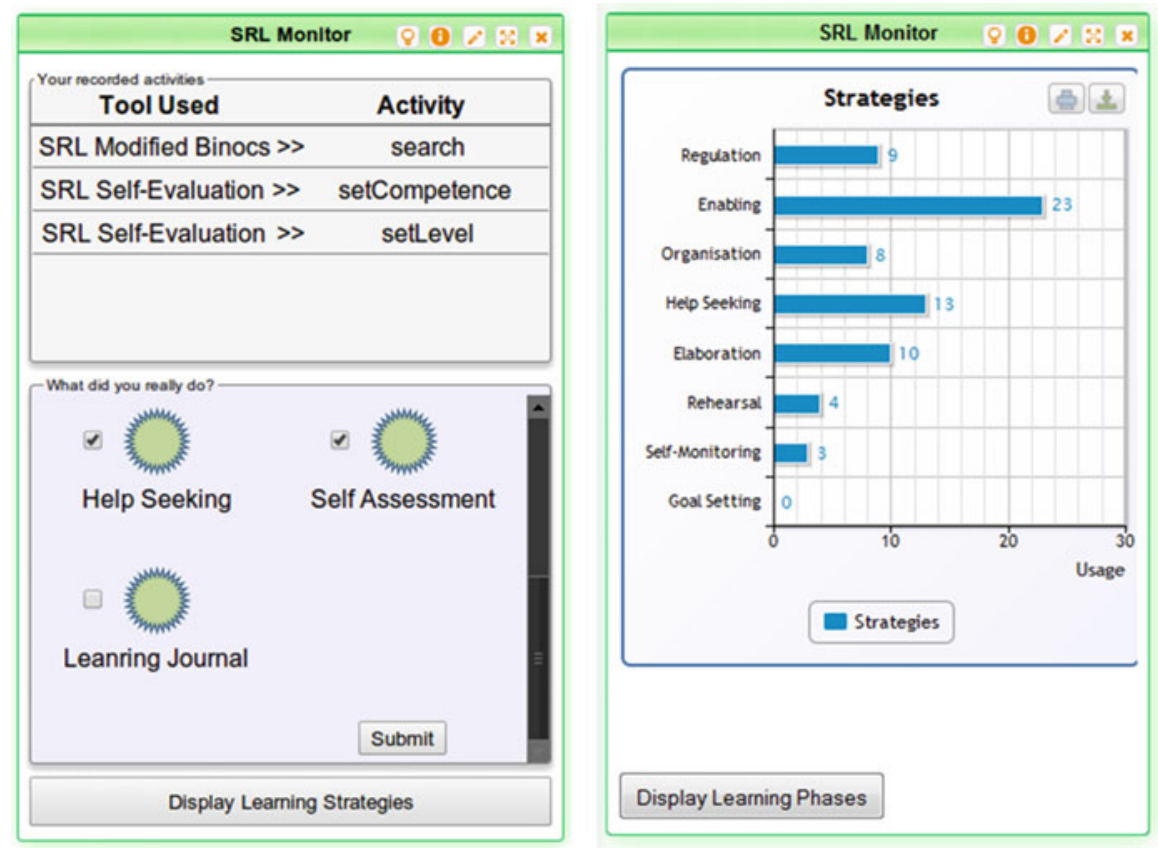

Fig. 10 SRL monitor. Screenshots of the two views of the SRL monitor widget are shown

\section{Evaluation Results, Challenges, and Barriers}

This section gives insight in the experiences made with the psycho-pedagogical model and the support strategies described above. It starts with an overview of evaluation studies of a few support strategies. Then it describes the experiences made in the test beds, in summer schools, and at conference workshops. More detailed evaluation results are described in the Chaps. 4-7 of this book.

\section{Selected Evaluation Results}

One evaluation study (Kroop 2013) focused on the usefulness of the developed Mashup Recommender (MR) widget (see section "Mashup Recommender", Fig. 7) and the SRL template it provided. The study compared teachers' and students' acceptance for the MR and its underlying SRL strategy. Altogether the findings show a broad acceptance of the MR concept by both teachers and students. When a group of teachers and a group of students independently from each other tested a variety of PLE-scenarios, the MR was recognised to be the only tool which consistently supports the creation of a PLE in a self-regulated learning way. Most 
scenarios for creating a PLE provide too much freedom (especially in selecting relevant learning tools from a broad variety of open educational resources), which causes students as well as teachers to be exhausted easily from (individually) evaluating and selecting learning tools. Consequently, the provided SRL guidance by the MR was perceived as a relief in creating a PLE. Although neither the teachers nor the students already felt familiar with the MR widget, teachers and students independently from each other appreciated the well-conceived idea to support SRL while creating a PLE. The discussions as well as the final ratings of the MR concept revealed that teachers were even more optimistic than students regarding the potential of the MR concept to improve and ease (self-regulated) learning. The findings of this study confirm the findings of the below described TPSRL study: Not only do students need guidance how to learn self-regulated but it is also important to provide support to the teachers and to train them how to (efficiently) introduce SRL to students. Another study (Dahn et al. 2013) concerns the Activity Recommender (AR) (see section "Activity Recommender"). The objective of this evaluation was to uncover strengths, weaknesses, and suggestions for improvement of the proposed approach and implementation. Therefore, usefulness of the learning support, usability of the developed software, and general feedback were questioned. The evaluation has been conducted in two different settings: The first evaluation took place in at the University of Koblenz-Landau in Germany and the second evaluation took place at the Shanghai Jiao Tong University in China. Summarising the results, there was a clear indication that the students appreciate guidance and help during the learning process. Some of the students liked the idea of getting recommendations for learning strategies and techniques for improving their learning. However, some students did not understand that recommendations are suggestions and not "must-do" instructions. Usability turned out as being the weakest point of AR. Without supervision and human support, many students had difficulties with the proper usage of the AR. Concluding these results, the approach of recommending learning activities is useful for and appreciated by students, whose SRL competences are not very low, but who do not apply SRL activities during their learning process. However, very weak self-regulated learners need sound introduction to SRL not only on pure technological level, but also in terms of human explanation, an introductory course, or videos.

\section{Results from the Conference Workshops}

The workshop series at the ICALT conferences in $2011^{10}$ and $2012^{11}$ aimed at investigating SRL in personal learning environments. The target audience consisted of researchers, developers, and users of learning environments who were interested

\footnotetext{
${ }^{10} \mathrm{http}: / /$ dbis.rwth-aachen.de/SRL-ROLE2011/

${ }^{11}$ http://dbis.rwth-aachen.de/S-ROLE2012
} 
in building individual learning environments. The accepted papers were presented at the workshop and published in the ICALT conference proceedings. The presentation session was followed by a group and plenary discussion.

The interactive format of the workshops helped to identify barriers of SRL. According to the participants, these barriers are mainly in the traditional educational system that does not cultivate the self-regulation competences early enough. This system designed for industrial purposes does not suit modern requirements anymore, as it kills motivation and creativity in learners. Individualisation of learning is a major challenge in education and rapid technological development brings new opportunities how to address it. A good SRL solution should be personalised and adaptive, providing a right balance between the learner's freedom and guidance, in order to both motivate and support the learner. This threshold is individual and context dependent. Therefore a spectrum of facilities is needed for various levels of SRL at different levels of education and in different contexts. Another key challenge is to prepare learners for lifelong learning when the teacher may not be available. They have to learn meta-cognitive skills, which are highly important. In this process, suitable scaffolding has to be taken into account.

The PALE workshops at the UMAP conferences in 2011 and 2012 provided opportunities to identify and discuss various issues related to topics like pedagogic conversational agents, responsive open learning environments, and learner modelling.

At PALE $2011^{12}$ (Perez-Marin et al. 2011) the ROLE-related discussions focused on the usefulness of PLEs in order to support SRL. A big challenge is to find an appropriate threshold between the learner control and tutor guidance. Personalised support can be provided by means of design templates and recommendations. In any case, this support has to be effective but not intrusive, considering the learner preferences. Moreover, these preferences are not static, but can change dynamically according to the context. Participants suggested focusing the research on two scenarios where learners are supposed to have certain capabilities to guide themselves: higher education and lifelong learning. It was also suggested to consider meta-cognitive competences as well as results of behavioural and cognitive psychology when designing learning environments.

To summarise the outcomes from PALE $2012^{13}$ (Herder et al. 2012), a lot of data can be collected in the educational process, but we need to find ways how to use it reasonably and to develop useful services that make the learning process more effective and efficient, e.g. by predicting student outcomes in order to intervene. Novel personalised services and environments are needed especially in lifelong and workplace educational settings, in order to support informal, self-regulated, mobile, and contextualised learning scenarios. A big challenge is also adaptation considering both long-term objectives and short-term dynamically changing preferences of learners. Here, open and inspectable learner models play an important role,

\footnotetext{
${ }^{12} \mathrm{http} / / /$ adenu.ia.uned.es/workshops/pale2011/

${ }^{13} \mathrm{http} / / /$ adenu.ia.uned.es/workshops/pale2012/
} 
considering also learner motivation and affective state. In the case of pedagogic conversational agents, personalisation is fostered by the use of dialogues adapted to the specific needs and level of knowledge of each student. Here and in mentorship systems trust and reputation play a crucial role.

At AHA $2012^{14}$ conference in Vienna a ROLE workshop ${ }^{15}$ on PLEs and the support of SRL took place. Workshop participants were mainly teachers and professors from Germany and Austria but also school consultants and technical support people from higher education institutions. At this workshop the participants had the opportunity to test and discuss a variety of ROLE tools for creating a PLE including tools for supporting SRL when creating a PLE. This workshop-session as well as an additional cross-validation workshop with students including teacher candidates from the University of Vienna revealed and confirmed success criteria as well as limitations and barriers for the uptake of the provided ROLE tools. The workshop results which explicitly included the perspectives and backgrounds of Germanspeaking countries and cultures were also presented and discussed with professionals from Guatemala at a Workshop on Cloud Education Environments (WCLOUD 2012) in Antigua, Guatemala (Kroop et al. 2012). Interestingly the experts from Guatemala shared the perspective of their colleagues from Germanspeaking countries, especially the need for SRL-supporting technology.

The essential success criteria for the uptake of the PLE tools were seen in the underlying pedagogical learning model: While participants were working with the provided tools and felt sometimes overwhelmed by the challenge to create a reasonable PLE, it became clear that a consistent model on SRL strategies and techniques as described in section "Models and Framework" was most needed. The idea to connect different stages of SRL (Planning, Searching, Learning, Reflecting) with corresponding ROLE tools for learning was seen most useful and most effective by almost all participants. A positive impact on learning by using SRL-supported PLE tools was especially seen in the following learning activities:

- Getting started with a learning task in a meaningful way.

- Keeping track of the own learning progress by following the provided learning strategy.

- Improved time management and reflection. Limitations for the uptake of the provided ROLE tools as well as doubts on the learning improvement by using these SRL-supported PLE tools were assumed as well and mainly addressed the personality, attitude, and motivation of a learner:

- Motivated learners will benefit from the provided PLE tools; it will improve their efficiency and outcome of learning.

\footnotetext{
${ }^{14}$ http://ahakonferenz.at/fruhere-aha/aha-2012/

${ }^{15}$ Sylvana Kroop, Marcel Berthold: Personalisierte Lernumgebungen. Unterstutzung von selbstreguliertem Lernen.
} 
- Very motivated learners will not need the technology-based SRL-support (e.g. the Recommender Widget, see section "Mashup Recommender", Fig. 7).

- Less motivated or weak learners will not benefit from the provided PLE tools.

Unfortunately the last assumption (about weak learners) was not well reasoned by the experts. But from the discussion context, it can be assumed that an intrinsic motivation of a learner is seen as a prerequisite to be successful when learning with PLEs. The idea that SRL-guidance provided by the PLE technology could trigger the motivation which is missed by weak learners was received with reservation.

Crucial barriers especially teachers raised for the uptake of the provided ROLE tools were belonging to time-consuming concerns for (learning) activities such as:

- To get in general used to the new PLE technology.

- To create a useful PLE in order to use it for the content taught in school and for the most ambitious request.

- To create and provide own SRL templates (see section "Mashup Recommender") which are adapted to a specific course or specific learning content.

Time-related issues in general can be seen as typical criteria for the uptake of any new technology. However, interesting is the fact that the participating teachers were aware of the possible time-wise burden and the additional effort compared to their used traditional learning and teaching but still accepted the uptake of the provided ROLE tools. They explicitly recommended the SRL-supporting PLE tools. Moreover, at the end of the workshop the involved teachers strongly expressed their wish to try out a PLE in their daily activities and thus created a mailing list in order to be informed and provided by further material, tutorials, online courses, or upcoming workshops on this topic. Altogether the experiences and findings from workshops gave important directions for the request and need of the research and development of innovative learning technology.

\section{Lessons Learned from the Test Beds}

Within the ROLE project, an instrument for understanding the perceptions of educators about SRL was devised. A questionnaire called "Teachers' Perception of Self Regulated Learning" (TPSRL ${ }^{16}$ ) was formulated, containing questions about how teachers perceive the SRL capabilities of their students, as well as about the challenges associated with teaching students with varied SRL competences. This questionnaire was circulated among the teachers of the Higher Education ROLE test beds. The TPSRL survey set out to explore which factors potentially influence teachers' assessments of their students SRL competence, how they see the

${ }^{16}$ http://fit-bscw.fit.fraunhofer.de/pub/bscw.cgi/39770946 
relationship between students' SRL competence and performance as well as which type of students in terms of SRL level the teachers prefer to teach.

According to the results of the TPSRL survey, the majority of the teachers that responded had an awareness of SRL and independent learning. Most of them also recognised the important function of SRL alongside its significance to them as well as to students. Some respondents related SRL to increased maturity and, therefore, an acceptance of responsibility for one's own learning. Several teachers regarded SRL as a joint venture, i.e. learning together with students and "discovery together'. SRL was also seen to influence students' ability to learn faster. Various teachers recognised that SRL could improve their students' reasoning or questioning abilities as well as their concentration power and, therefore, their capacity to learn. Some alluded to a teacher's moral duty to guide/show "right" path using SRL techniques, thus adding to the all round development of students, i.e. implying that it was an implicit responsibility of all teachers.

The strategies the respondents to the survey use in order to motivate and support students in becoming self-regulated are quite varied. One of these strategies consists of providing specific academic study skills facilities outside the classroom, available as face-to-face as well as via online support from the university, i.e. blended approach. Additionally, several teachers direct students to online and/or library-based "learning to learn" resources. Some teachers prefer to offer less help to their students, thus encouraging them to take more initiatives and learn for themselves. "Leading by example" is also a popular strategy: the teacher indicates or offers different approaches to resolving subject-based problems but leaves the students to choose their own learning path. Finally, the majority of the respondents agreed that encouraging active learning through peer collaboration helps motivate SRL of their students. In particular, some teachers promote working together with their students, e.g. through semi-directed projects, or they encourage group work.

The survey was also quite revealing with regard to some of the challenges in motivating higher education students to become self-regulated learners. Several respondents stated that many students are simply not equipped to learn at an $\mathrm{HE}$ level. They also mentioned that their students are reluctant to accept new methods of learning or change in their outlook on learning. On the other hand, most students expect to be provided with precisely defined learning materials and strategies by their teachers. One of the themes that emerged was that inspiring groups of students that have mixed learning skills is challenging in itself. Students with fewer SRL skills require more time to assimilate information or discover new methods of learning. This has implications for the teacher in terms of effort required to meet the needs of the entire spectrum of learning skills in the classroom. Most importantly, the teacher may not have enough knowledge, experience, or personal confidence to include SRL in the delivered curriculum time frame. 


\section{Experiences in the Summer Schools}

In the years 2010-2012 several workshops on SRL were organised, mainly for Ph. D. students in the TEL area at the JTEL Summer Schools. Three key target groups were considered at these events, namely learners, teachers, and developers. At the workshops the objective was to demonstrate the conceptual and technical solutions for personalised support of SRL. In the introductory part we aimed to explain how psycho-pedagogical theories impact the design of learning environments, considering principles of SRL. We emphasised the role of decision making for the quality of the learning outcome and that it should be supported properly to optimise learning for benefit of the learner. Specific support strategies for SRL were explained taking into account the various SRL concepts. The participants tried out the ROLE software aiming to create a PLE. Experience from these events has shown that Ph.D. students understood the ROLE approach quickly and managed to design their PLEs without bigger problems.

In the practical part they elaborated approaches for personal support in small groups. The approaches were made with paper-and-pencil or with respective tools on their laptops. Each group presented their results followed by a discussion with the other participants. The group work was active and creative. However, it also turned out that it was really difficult for the students to find good and innovative solutions. As a conclusion it can be reported that the concept of personalised support for SRL can be explained to Ph.D. students, but it is very difficult that they find new solutions in a 3-h workshop.

In 2010 we conducted a survey to test the impact of choice architecture on the responses of people and to find out what $\mathrm{Ph} . \mathrm{D}$. students think on some issues in TEL. Our respondents (advanced learners) mostly thought that too much freedom for the learner may be overwhelming and contra productive. Similarly, they agreed that learners needed pedagogical assistance. Finally, almost all of them appreciated availability of a competent tutor. In addition to these findings we could easily see how important it is to find good explanations of SRL concepts in order to achieve a common understanding. Slight changes in wording may dramatically change responses. At the same time this demonstrated that to identify real opinions and preferences of people may be a tricky issue and the concept of choice architecture can influence them essentially.

\section{Conclusion}

The ROLE project has aimed to achieve progress beyond the state of the art in usercentric responsive and open learning environments. A key objective of this intention was the development of a psycho-pedagogical framework. The most important goal of this framework is to support learners to learn in a self-regulated way in responsive open learning environments. Based on this framework, a variety of 
support strategies have been developed. This approach is grounded on a literature review on SRL and experiences made in the test beds and in workshops with students, teachers, and researchers.

One of the most important findings was that adopting the self-regulated way of learning can be very difficult especially for weak learners of learners not used to freedom in their learning process. In such situation technological support strategies alone are not sufficient and not successful. Therefore, a holistic support strategy is needed, which includes several factors: (1) Material (e.g. videos) that motivates learners and raises their attention for SRL. (2) Courses that provide step-to-step introduction to SRL, so that learners can practice and get use to a new form of learning. (3) Preconfigured environments that already support SRL, so that the learner does not have to start from scratch. (4) Peers should be included in the learning situation, which leads to communication and reflection on the own learning process. (5) Finally teachers (if available) should take care to support learners. It turned out that also teachers need introduction and awareness for SRL, because not all teachers do fully understand the concept of SRL.

Five key aspects have been identified as essential for the psycho-pedagogical approach: Personalisation, degree of guidance, motivation, meta-cognition, and collaboration. Each support strategy takes into account at least one of these aspects. The SRL process model describes the learning process and thus serves as a backbone for support strategies. Based on these aspects, several support strategies have been developed (see section "Support Strategies"). However, these strategies are just examples demonstrating how support for SRL can be provided. Actually there is still room for new and more sophisticated support strategies. Future research and development can (and should) be done in this field. Taking into account the theoretical approaches described in this chapter, future possibilities for supporting learners will emerge.

One of the limitations we faced during the project was the technology-based assessment of SRL competences. It turned out that automatically assessing SRL competences (e.g. by monitoring the learner when using the learning environment) is much more difficult than expected. Especially in this field there is room for further research. In order to overcome this problem, teachers were asked to estimate the SRL competences of their students and also students were asked to self-estimate their SRL competences. However, a method to automatically determine the SRL competences would still improve the learning process and would give new possibilities to support the development of SRL competences and to personalise the recommendations of learning resources and activities.

Acknowledgements The research work described in this chapter is partially funded through the ROLE Integrated Project (grant agreement no 231396); part of the Seventh Framework Programme for Research and Technological Development (FP7) of the European Union in Information and Communication Technologies.

All people involved in the ROLE project and not listed as authors merit special thank, especially Milos Kravcik, Bernd Prunster, Marcel Berthold, Karin Fruhmann, Andreas Kiefel, and Pablo Lachmann. 
Open Access This chapter is distributed under the terms of the Creative Commons Attribution Noncommercial License, which permits any noncommercial use, distribution, and reproduction in any medium, provided the original author(s) and source are credited.

\section{References}

Albert D, Schrepp M. Structures and design of an intelligent tutoring system based on skill assignments. In: Albert D, Lukas J, editors. Knowledge spaces: theories, empirical research, and applications. Mahwah: Lawrence Erlbaum; 1999. p. 179-96.

Anderson JR. The expert module. In: Polson MC, Richardson JJ, editors. Foundations of intelligent tutoring systems. Hillsdale: Lawrence Erlbaum; 1988. p. 21-53.

Aviram A, Ronen Y, Somekh S, Winer A, Sarid A. Self-regulated personalized learning (SRPL): developing iClass's pedagogical model. eLearning Papers. 2008;9(9):1-17.

Bannert M. Effects of reflection prompts when learning with hypermedia. J Educ Comput Res. 2006;35(4):359-75.

Berthold M, Lachmann P, Nussbaumer A, Pachtchenko S, Kiefel A, Albert D. Psycho-pedagogical mash-up design for personalising the learning environment. In: Ardissono L, Kuflik T, editors. Advances in user modeling, lecture notes in computer science, vol. 7138. Berlin: Springer; 2012. p. 161-75.

Boekaerts M. Self-regulated learning: where we are today. Int J Educ Res. 1999;31(6):445-57.

Brusilovsky P, Kobsa A, Nejdl W, editors. The adaptive web. Berlin: Springer; 2007.

Corbett AT, Koedinger KR, Anderson JR. Intelligent tutoring systems. In: Helander MG, Landauer TK, Prabhu PV, editors. Handbook of human-computer interaction. Amsterdam: Elsevier; 1997. p. 849-74.

Covington MV. Goal theory, motivation, and school achievement: an integrative review. Annu Rev Psychol. 2000;51:171-200. doi:10.1146/annurev.psych.51.1.171.

Dabbagh N, Kitsantas A. Supporting Self-regulation in student-centered web-based learning environments. Int J e-Learn. 2004;3(1):40-7.

Dahn I, Kiefel A, Lachmann P, Nussbaumer A, Berthold M, Albert D. The ROLE learning ontology and its application in recommenders for self-regulated learning. Int J Innov Qual Learn (INNOQUAL). 2013;1(2):52-63.

Dalsgaard C. Social software: e-learning beyond learning management systems. Eur J Open Dist E-Learn. 2006;14(2):50-71.

DeBra P, Smits D, Stash N. The design of AHA! In: Proceedings of the ACM hypertext conference, 2006, ACM, New York, p. 133-14.

Dillenbourg P. Introduction: what do you mean by "collaborative learning"? In: Dillenbourg P, editor. Collaborative learning. Cognitive and computational approaches. Oxford: Elsevier; 1999. p. 1-19.

Ebner M, Taraghi B (2010) Personal learning environment for higher education a first prototype. In: World conference on educational multimedia, hypermedia and telecommunications (ED-MEDIA), AACE, Chesapeake, p. 1158-66.

Fruhmann K, Nussbaumer A, Albert D. A psycho-pedagogical framework for self-regulated learning in a responsive open learning environment. In: Hambach S, Martens A, Tavangarian D, Urban B, editors. Proceedings of the international conference eLearning Baltics science (eLBa Science 2010). Rostock: Fraunhofer; 2010.

Guo Y, Rui J, Zhou H (2010) Pervasive and personal learning environment using service-oriented architecture: a framework design. In: International conference on networking and distributed computing, IEEE Computer Society, Los Alamitos, p. 153-5.

Hattie JAC. Visible learning a synthesis of over 800 meta-analyses relating to achievement. London: Routledge; 2009. 
Heller J, Steiner C, Hockemeyer C, Albert D. Competence-based knowledge structures for personalised learning. Int J E-Learn. 2006;5(1):75-88.

Herder E, Yacef K, Chen L, Weibelzahl S, editors. Workshop and poster proceedings of UMAP 2012, CEUR workshop proceedings; 2012, vol. 872. http://ceur-ws.org/Vol-872/

Hover KM, Steiner C. Adaptive learning environments: a requirements analysis in business settings. Int J Adv Corp Learn (iJAC). 2009;2(3):27-33. doi:10.3991/ijac.v2i3.956.

Issing LJ. Issing J, Klimsa P. In: Informationen und Lernen mit Multimedia und Internet, Lehrbuch fur Studium und Praxis. 3rd ed. Weinheim: Beltz; 2002. p. 151-78.

Kitsantas A. Test preparation and performance: a self-regulatory analysis. J Exp Educ. 2002;70(2): 101-13.

Kroop S. Evaluation on students' and teachers' acceptance of widget-and cloud-based personal learning environments. J Univers Comp Sci. 2013;19(4):2150-2171, http://www.jucs.org/ jucs_19_14

Kroop S, Berthold M, Nussbaumer A, Albert D (2012) Supporting self-regulated learning in personalised learning environments. In: Proceedings of the 1st International workshop on cloud education environments (WCLOUD 2012), CEUR Workshop Proceedings, vol. 945, p. 47-52. http://ceur-ws.org/Vol-945/

Locke EA, Latham GP. Building a practically useful theory of goal setting and task motivation. Am Psychol. 2002;57(9):705-17. doi:10.1037//0003-066X.57.9.705.

Mandl H, Friedrich H. Handbuch Lernstrategien. Göttingen: Hogrefe; 2006.

McConnell D. Implementing computer supported cooperative learning. 2nd ed. London: Routledge; 2000.

Nussbaumer A, Steiner C, Albert D. Visualisation tools for supporting self-regulated learning through exploiting competence structures. In: Proceedings of the international conference on knowledge management (IKNOW 2008)

Nussbaumer A, Berthold M, Lachmann P, Kiefel A, Kravcik M, Kroop S, Mikroyanidis A. ROLE deliverable D6.1(M48): common psycho-pedagogical framework. ROLE Project; 2013. http:// www.role-project.eu/Deliverables

Nussbaumer A, Dahrendorf D, Schmitz HC, Kravcik M, Berthold M, Albert D. Recommender and guidance strategies for creating personal mashup learning environments. J Comp Sci Inf Syst (ComSIS). 2014;11(1).

Paulsen M. Experiences with learning management systems in 113 European institutions. Educ Technol Soc. 2003;6(4):134-48.

Perez-Marin D, Kravcik M, Santos OC, editors. Proceedings of the international workshop on personalization approaches in learning environments (PALE2011), CEUR Workshop Proceedings, vol. 732; 2011. http://ceur-ws.org/

Pintrich PR. Motivational and self-regulated learning components of classroom academic performance. J Educ Psychol. 1990;82(1):33-40. doi:10.1037/0022-0663.82.1.33.

Plass JL. Supporting visual and verbal learning preferences in a second-language multimedia learning environment. J Educ Psychol. 1998;90(1):25-36. doi:10.1037/0022-0663.90.1.25.

Popescu E, Cioiu D. eMUSE-Integrating Web 2.0 tools in a social learning environment. In: Leung H, Popescu E, Cao Y, Lau RWH, Nejdl W, editors. Advances in web-based learningICWL 2011, 10th International Conference, Hong Kong, China, December 8-10, 2011, vol. 7048. New York: Springer; 2011. p. 41-50. doi:10.1007/978-3-642-25813-8.

Roberts MJ, Erdos G. Strategy selection and metacognition. Educ Psychol. 1993;13(3/4):259-66.

Ryan R, Deci E. Intrinsic and extrinsic motivations: classic definitions and new directions. Contemp Educ Psychol. 2000;25(1):54-67. doi:10.1006/ceps.1999.1020.

Softic S, Taraghi B, Ebner M, Vocht L, Mannens E, Walle R. Monitoring learning activities in PLE using semantic modelling of learner behaviour. In: Holzinger A, Ziefle M, Hitz M, Debevc M, editors. Human factors in computing and informatics, lecture notes in computer science, vol. 7946. Berlin: Springer; 2013. p. 74-90. doi:10.1007/978-3-642-39062-3.

Steiner C, Nussbaumer A, Albert D. Supporting self-regulated personalised learning through competence-based knowledge space theory. Policy Fut Educ. 2009;7(6):645-61. 
Treier M. Personale Voraussetzungen fur das Lernen mit Neuen Medien. Evaluation und Gestaltung im Zusammenhand mit der Implementierung einer Bildungsplattform in einem Konzern. Hamburg: Dr. Kovac; 2004.

Tseng J, Chu H, Hwang G, Tsai C. Development of an adaptive learning system with two sources of personalization information. Comput Educ. 2008;51(2):776-86. doi:10.1016/j.compedu. 2007.08.002.

Waite S, Davis B. Developing undergraduate research skills in a faculty of education: motivation through collaboration. Higher Educ Res Dev. 2006;25(4):403-19. doi:10.1080/ 07294360600947426.

Weinstein CE, Husman J, Dierking DR. Self-regulation interventions with a focus on learning strategies. In: Boekaerts M, Pintrich PR, Zeidner M, editors. Handbook of self-regulation. Burlington: Elsevier Academic Press; 2005. p. 727-47.

Winne P, Hadwin A. The weave of motivation and self-regulated learning. In: Schunk D, Zimmerman B, editors. Motivation and self-regulated learning: theory, research, and applications. New York: Lawrence Erlbaum; 2008. p. 297-314.

Zimmerman BJ. Becoming a self-regulated learner: an overview. Theory Into Practice. 2002; 41(2):64-70. doi:10.1207/s15430421tip4102ไ2. 